\title{
Vivencias en voz baja: Género, público y privado en poblaciones rurales de Rio Grande do Norte (Brasil)*
}

\author{
Mónica Fernanda Figurelli**
}

\begin{abstract}
Resumen
Este artículo surge de un trabajo de campo realizado en poblaciones rurales localizadas en tierras que en un pasado pertenecieron a un latifundio ganadero y algodonero, al sur de la región agreste de Rio Grande do Norte, Brasil. A partir de una investigación sobre un conflicto laboral ocurrido en dicho latifundio en la década de sesenta, durante la sindicalización de los/as trabajadores/as rurales del lugar, en este texto atiendo los momentos del trabajo de campo compartidos con las mujeres de esa región. Me interesa enfocar el universo social que nuestras interacciones y lo que me contaban permiten vislumbrar. Frecuentemente, los varones fueron los recomendados para interactuar con quien no era de allí y contar sobre las cuestiones que me interesaban y que eran de conocimiento público; no competía a las mujeres esa interacción, ni ese poder de acceso a la palabra de interés general. Sin embargo, en un ámbito de mayor intimidad, sí accedían a esa palabra. Con ellas descubrí una dinámica social diferente a la que observaba con los varones, la cual no hubiera podido apreciar por fuera de sus redes cotidianas de sociabilidad. Con este artículo procuro mostrar ese mundo público que se construye en el ámbito doméstico o en aquel para cuyo acceso se requiere algún grado de familiaridad. Pretendo, con una perspectiva de género, aportar a una mirada crítica de la dicotomía público-privado.
\end{abstract}

Palabras clave: Ámbito doméstico, Público-privado, Narrativas, Poblaciones rurales, Rio Grande do Norte.

\footnotetext{
* Recibido el 15 abril 2019, aceptado el 14 junio 2021. Agradezco a lxs evaluadorxs anónimxs las atentas sugerencias que me ayudaron a mejorar el artículo.

** Investigadora Adjunta del Consejo Nacional de Investigaciones Científicas y Técnicas (CONICET), Universidad Nacional de Misiones (UNaM), Misiones, Argentina; integrante del Núcleo de Antropología da Política (NuAP), del PPGAS-MNUFRJ, Rio de Janeiro, RJ, Brasil. ferfigus@yahoo.com.ar / https://orcid.org/0000-0003-2813-381X
} 
Whispered experiences: Gender, Public and Private among rural populations in Rio Grande do Norte, Brazil

\begin{abstract}
This article stems from fieldwork with rural populations living on what was once an enormous livestock and cotton plantation in the Agreste region of Rio Grande do Norte, Brazil. Drawing on a study of a labor conflict surrounding the unionization of rural workers there in the 1960s, the article examines moments of fieldwork involving the region's women. I am interested in focusing on the social universe I could see through these women's statements and my interactions with them. During my fieldwork, men were usually the ones to talk to outsiders and discuss issues that interested me and of public knowledge. Women would not engage in such interactions and did not have the power to speak about issues of general interest. In more intimate settings, however, their voices emerged. With these women, I discovered a social dynamic different from that observed with the men, a dynamic I would not have been able to comprehend outside their daily sociability networks. In this article, I intend to show the public world that is constructed within the domestic realm, or in other spaces where familiarity is a condition for access. The goal is to contribute to a critical perspective on the public-private dichotomy from a gender perspective.
\end{abstract}

Keywords: Domestic realm, Public-private, Narratives, Rural populations, Rio Grande do Norte. 
Introducción

A las tierras del assentamento [asentamiento] de reforma agraria "Jorge Fernandes", al sur agreste de Rio Grande do Norte, llegué con una pregunta sobre el conflicto sindical que había ocurrido en ese lugar durante la dictadura militar ${ }^{1}$ :

"¿Tú recuerdas, aquí, una época que vino el sindicato y que hubo mucha persecución, en el 64 (...)?” Le pregunté a Edna, una antigua habitante del lugar que, refiriéndose a las reuniones actuales, me respondió:

"Me acuerdo, pero el que anda en ese asunto del sindicato es mi marido, es él el que sabe".

“¿Tú no ibas a las reuniones?”, pregunté.

"No, es él el que va, porque es él el que es asentado de acá, entonces esas cosas es más con él, reunión es más con él. Cuando yo quiero ir voy, cuando no quiero no voy" (Edna, entrevista, 15 de abril, 2009).

A pesar que me remitió a su marido, inmediatamente después Edna comenzó a hablar de los asuntos que los asentados tratarían en la reunión del próximo sábado. El tema no era desconocido por ella, pero no era Edna la indicada para hablar de aquello, al menos no con alguien de afuera. Tampoco era la persona sugerida para ser "entrevistada". Responder sobre reuniones sindicales a una desconocida, con grabador mediante, no era una situación en la que se sentía a gusto, aunque yo fuera una mujer. Le parecía más adecuado que en ese escenario estuviese su marido.

Como Edna, también otras mujeres me indicaron a determinados varones para que les hiciera mis preguntas sobre conflictos sindicales y temas asociados, incluso cuando ellas sabían al respecto. De este modo, con el pasar del tiempo, modifiqué mi pregunta principal por otra más inclusiva y adecuada para quienes vivían en el lugar. Aun así, los varones siguieron siendo los más recomendados para contarme sobre lo que investigaba. A Edna y a la gran mayoría de las mujeres llegaría por otro camino.

Esa nueva pregunta se asoció con Belém, la gran propiedad rural que en el pasado ocupaba el territorio en el que viven actualmente. En ella habitaban sus propietarios y quienes se ocupaban como fuerza de trabajo, principalmente en las plantaciones de algodón y en el cuidado del ganado, actividades centrales para la economía de la propiedad. La gran mayoría de esos trabajadores eran los llamados moradores y sus familias ${ }^{2}$. Los moradores tenían su casa en la propiedad, la cual incluía un espacio para sus cultivos de auto-subsistencia, el llamado roçado [rozado]. Algunos también criaban animales para su propio consumo. En contrapartida, debían trabajar gratuitamente para el propietario una vez a la semana (lo que denominaban diaria) y pagar anualmente un foro, que definieron como un arrendamiento. Además debían plantar algodón, el cual debía ser vendido en una transacción desventajosa al dueño de la propiedad.

El objetivo de mi investigación, realizada entre los años 2008 y 2010, versaba sobre las formas de aprehensión de un "conflicto" ocurrido en el latifundio en cuestión durante el proceso de sindicalización de trabajadores rurales que, en años previos a la dictadura militar, se desarrollaba allí $y$ en otras zonas de Rio Grande do Norte. La investigación incluyó un trabajo de campo multisituado, en el cual combiné permanencia prolongada en el asentamiento Jorge Fernandes (desde donde me trasladé también hacia diferentes localidades cercanas), entrevistas (más de cincuenta, en gran parte a varones, que fueron grabadas y transcriptas) e indagación en archivos. Los/as entrevistados/as fueron seleccionados/as a partir de las recomendaciones que las personas del lugar fueron haciendo, si bien en algunos casos, como en el de varias mujeres, la selección fue por edad y permanencia en la región. Las situaciones a las que me aboco en este artículo surgieron de algunas entrevistas grabadas, realizadas a mujeres de mayor edad, pero principalmente se constituyen por los momentos más cotidianos e informales de mi trabajo de campo, que derivaron

\footnotetext{
1 Para preservar la privacidad de mis interlocutores/as en el campo, en este artículo todos los nombres propios y la mayor parte de los de lugares han sido cambiados. Las traducciones de las citas de entrevistas fueron hechas por la autora.

2 También se encontraban trabajadores de mayor jerarquía. Sobre estas grandes propiedades de ganado y algodón en el Nordeste de Brasil ver Cascudo (1956), Johnson (1971), Bastos (s/f), Almeida y Esterci (1977a, 1977b).
} 
de mi estadía en una casa del asentamiento y de las relaciones personales que entablé a partir de esa experiencia.

Durante el trabajo de campo fui guiada predominantemente hacia el relato de los varones. Pasé tiempo con ellos en conversaciones sobre Belém, los conflictos sindicales, la dictadura militar y varias otras cuestiones. Pero, en su mayor parte, mi tiempo fue compartido con el de otras mujeres, principalmente con aquellas en cuya casa me hospedaba y con las que vivían cerca de allí. Con ellas compartía las comidas, el descanso de las siestas, el rato posterior a la cena y por lo general todos los momentos en los que no indagaba sobre mi tema de investigación. Ellas también me acompañaban a hacer entrevistas, sobre las que luego dialogábamos, y a "pasear" y conocer el lugar en el que estábamos. ${ }^{3}$

Luego de mi pregunta sobre Belém, los hombres me contaban una "historia", o más de una, que las mujeres reconocían y de la que eran parte, pero, por lo general, esas historias no aludían a espacios de circulación de mujeres. Tampoco eran ellas quienes protagonizaban esos relatos, los cuales versaban principalmente sobre actividades en las que se destacaban los hombres. Los varones me contaban de sus experiencias, o de las de sus padres y abuelos, en las que las mujeres ocupan un lugar secundario. De esto me interesa destacar dos cuestiones: eran los varones los recomendados para contar sobre Belém, es decir, sobre algo que tenía una existencia más allá de sus propias experiencias, y los recomendados, asimismo, para contar a alguien de afuera. Su acceso a una palabra que se expandía a fronteras más amplias también instalaba asuntos que adquirían un interés público, y esos asuntos se referían a actividades en las que ellos despuntaban. De modo que si me hubiera guiado por mis preguntas y por las redes de recomendaciones que se conformaron a partir de ellas, una experiencia considerable de las mujeres con quienes conviví en mi trabajo de campo no habría sido contemplada, y en un ámbito donde las actividades de mujeres y hombres están en gran medida diferenciadas, mi investigación, sin haberlo percibido, sólo hubiera dado cuenta de la experiencia masculina. ${ }^{4}$

Las relaciones que establecí desde un lugar más personal con algunas mujeres del lugar me abrieron el acceso a otras narrativas y actividades. A pesar de florecer, por lo general, en un ámbito doméstico, en el que me involucraba no tanto desde mi lugar institucional y mis preguntas de investigación como desde mi nombre propio, esas experiencias evocaban diversos espacios de sociabilidad de mujeres, tanto del pasado como del presente. A partir de los ámbitos domésticos y de las relaciones personales pude ver que la construcción del universo público no era únicamente masculino, que tampoco era uno solo y que, en lo que hace a este sur agreste nordestino, la clásica distinción entre lo público y lo doméstico-la cual de diferentes maneras opera en varios de nuestros estudios- se reveló más como una valoración masculinamente centrada que como una clasificación analíticamente útil. ${ }^{5}$

En la antropología feminista existe una importante discusión en torno a la dicotomía público/doméstico. Trabajos pioneros como los de Rosaldo (1974) y Ortner (1979), entre otros, se valen de esa dicotomía para explicar la subordinación de la mujer que consideran universal. En este planteamiento la esfera doméstica es entendida en torno al vínculo madre-hijo/a. Por su rol destacado en la crianza, las mujeres son identificadas en los diferentes sistemas culturales con la esfera doméstica de la actividad, subsumida en la esfera pública. La mujer estaría "confinada",

\footnotetext{
${ }^{3}$ No se considera apropiado que las mujeres se desplacen solas por el lugar. En mi caso, a pesar de haber llegado sola desde lejos, circulé sin compañía en muy pocas ocasiones. Teresinha, mi anfitriona de mayor edad, siempre pedía a alguien - por lo general a sus nietos- que me acompañara a hacer mi trabajo. La mayoría de las veces me acompañó Marcela, su nieta de dieciocho años.

4 Sobre ese punto, ver Figurelli (2011, 2021). Como señalé en Figurelli (2021), el reconocimiento de esta cuestión ha sido un pilar en trabajos vinculados a la historia, el género y la memoria, principalmente en la historia oral. De diferentes maneras, éstos han partido de la crítica a una epistemología que excluye sistemáticamente la experiencia de las mujeres -o más apropiadamente, de quienes desempeñan los papeles socialmente construidos como femeninos-, de la consecuente necesidad de "dar voz" a esas mujeres y de incorporar sus narrativas a la investigación científica (e.g. Jelin, 2011; Leydesdorff; Passerini; Thompson, 2017; Perrot, 2008).

5 Esa índole masculina de la oposición, que excluye lo doméstico del interés público, ha sido apuntada en otros trabajos (e.g. Fraser, 1997; Okin, 2008).
} 
como señala Ortner (1979), a esa esfera. De acuerdo con Rosaldo (1974), allí donde la oposición es más fuerte, las mujeres son más subordinadas.

Diferentes críticas se han hecho a ese modelo explicativo (e.g. Moore, 2009; Rosaldo, 1980; Strathern, 1984; Yanagisako, 1979). Además de su formalismo y pretendido universalismo, varios de los cuestionamientos se han dirigido a su concepción sobre lo doméstico. La variabilidad de organizaciones domésticas, así como de las nociones de "madre", "mujer" y maternidad ha sido apuntada al rebatir la identificación de esa esfera con las instituciones organizadas alrededor del vínculo madre-hijo/a. Además, se ha destacado la variedad de valoraciones de lo doméstico. Strathern (1984), por ejemplo, señala que, a diferencia del menosprecio occidental del mismo, en Hagen -Papúa Nueva Guinea- las mujeres son personas en su totalidad en el dominio doméstico sin necesidad de recurrir a otros dominios para pensar su participación social. ${ }^{6}$

Este trabajo se suma a la revisión de lo doméstico y pretende desacreditarlo como par de la dicotomía. Más que un "confinamiento" me dirijo a mostrar las sociabilidades que, en el caso estudiado, el espacio doméstico supone.

$\mathrm{Si}$ en las relaciones que se tejen en las tierras de la antigua Belém hay diferentes líneas de separación entre actividades y narrativas masculinas y femeninas sería un error tildar esas líneas como divisorias entre lo público y lo privado. Estudios hechos en diferentes sitios han permitido ver la compleja trama de relaciones sociales que se pone en juego en los ámbitos mal llamados "privados", que son por lo general aquellos de mayor circulación de mujeres. Para este artículo quisiera destacar los trabajos de Abu-Lughod (1999), Ramanujan (1991) y Grima (1991), quienes analizan diversas formas de narrativas orales de mujeres que ocurren preponderantemente en ámbitos domésticos. En lugar de relegar a un segundo plano esos ámbitos poco atendidos en investigaciones anteriores, los/as autores/as les dan primacía y dejan ver, además, su profundo carácter público. Al referirse a los relatos de mujeres en ámbitos domésticos de Karnataka, Ramanujan (1991) alude al "contra-sistema" que éstos revelan, mientras que Grima (1991) reflexiona sobre la construcción de reputaciones y los modos de pertenencia a la comunidad que las narrativas de historias de vida y de eventos personales de desgracia implican entre las mujeres pastunes y Abu-Lughod (1999), que investiga en tribus beduinas del desierto occidental de Egipto, considera los desafíos al orden moral que suponen los poemas conocidos como ghinnāwas, los cuales se recitan en contextos de intimidad.

Teniendo en cuenta los trabajos citados y otros que desde diferentes lugares cuestionan la separación entre lo público y privado, lo doméstico y político, lo íntimo y jurídico (e.g. Carsten, 2000; Elias, 1996; Figurelli, 2017; Marcelin, 1999; Marques, 2007; Palmeira; Barreira, 2006; Weber, 2006), en este artículo me interesa pensar lo público y lo privado en lo referente al género. Como señalé anteriormente, me detengo en el mundo público que se construye en el ámbito doméstico o en aquel cuyo acceso requiere algún grado de familiaridad. Particularmente, enfoco cómo desde formas más íntimas de relacionamiento, las actividades y relatos de las mujeres me revelan sus espacios de sociabilidad y me permiten apreciar un universo público que a primera vista permanece oculto. A pesar de no ser las recomendadas para contar sobre Belém, cuando las mujeres me hablan sobre sus diferentes tareas, en la agricultura, en su casa o en la casa de farinha [casa de harina], cuando permanezco con ellas en el hogar de mi anfitriona, o cuando las

\footnotetext{
6 En estudios que exploran espacios sociales ocupados por mujeres negras (lo cual, vale aclarar, no corresponde al caso en estudio), lo doméstico también se vuelve una cuestión a ser revisitada. En Davis (2016), por ejemplo, quien se centra en la esclavitud en los Estados Unidos, la significación de lo doméstico no se desliga de consideraciones sobre clase y raza. Mientras el patrón dominante del capitalismo industrial establecía la separación entre la economía doméstica y la economía pública, en la que la "mujer" era separada del mundo productivo y definida como "madre" y "ama de casa" términos éstos que conllevaban la inferioridad social-, las comunidades esclavas se regían por un patrón diferente. Lo doméstico era el único espacio donde los/as esclavos/as podían desarrollarse como seres humanos, de modo que ese ámbito tomaba centralidad en su vida social. Las mujeres negras, que eran obligadas a trabajar al igual que los varones, no eran disminuidas por sus funciones domésticas, al contrario, en esas funciones, tanto hombres como mujeres, ocupaban un lugar significativo en la comunidad esclava (Davis, 2016). Desde otro ángulo, si miramos en Gonzalez (2018) el lugar social de la "madre negra", podemos observar el espacio doméstico como el ámbito en el que las mujeres negras "pone(n) el pie en la raza dominante" (Gonzalez, 2018:576), ya que, de acuerdo con la autora, al ejercer la función materna, ellas construyen el imaginario de los niños brasileños.
} 
acompaño por sus zonas de circulación más allá de sus trabajos, ellas no exponen un mundo "privado", al contrario, muestran una intensa dinámica social.

En las páginas que siguen me detendré en algunas situaciones con las mujeres del lugar. Destacaré primero sus narrativas sobre sus trabajos, continuaré con la dinámica cotidiana que tenía lugar en la casa de mi anfitriona durante mi investigación y finalizaré con sus prácticas religiosas. Mostraré que en esos encuentros, en sus casas o en la capilla, más que una orientación particular de sus actividades, fuera de la vida pública del lugar, las mujeres manifiestan sus formas de participación colectiva y sus modos de contar aquello.

\section{En el rozado, en la casa, en la feria}

Ana vive próxima a Celine y es su tía, una de las hermanas de su madre. Al momento de mi trabajo de campo rondaba los 68 años. Llegamos a su casa para visitarla y por mi pedido hubo un momento de "entrevista", de conversación grabada, si bien Celine no veía el sentido de aquello. Ana vive en Manaus, una de las varias "comunidades" -como se refieren sus habitantes a esas pequeñas localidades rurales- en las que hoy se dividen las tierras de la antigua Belém. Gran parte de quienes residen en esas comunidades son los antiguos moradores y sus familias, que compraron pequeñas parcelas en el lugar.

El asentamiento en el cual me hospedé para hacer mi investigación se erige en aquellas tierras, junto a las comunidades, desde el año 2001, como consecuencia de una ocupación organizada desde el sindicato de trabajadores rurales de Bom Jesus (el municipio donde está el asentamiento). Allí fui acogida en la casa de Gregório, el presidente de ese sindicato y antiguo morador de Belém, y de su esposa Teresinha, también una antigua habitante del lugar con quien pasé la mayor parte del tiempo durante mi trabajo de campo.

A Celine la conocí en la casa de Teresinha, un domingo que había ido a visitarla junto con Maria Clara -su prima hermana- y la familia de esta última. Las dos primas transitaban la década de sus cuarenta. Teresinha, que en ese momento tenía sesenta y dos años, conocía a los padres de ambas. Ese día, Celine me invitó a Manaus, donde vivía, y fue así como logré llegar a esa comunidad, que dista a unos pocos kilómetros del asentamiento.

Entre lo destacado por Ana cuando le pregunté sobre el pasado en aquel lugar se encontraba su actividad en el rozado.

Yo plantaba y cosechaba. Plantar todo el día así era pesado y yo plantaba todo el día. Pero era mucha gente trabajando junta (...) Si uno iba a cavar el terreno, juntaba ocho, diez hombres para cavar un terreno de esos en un día y las mujeres, todito, iban a plantar. Entonces, otro día ya era otro, las mujeres y los hombres nuevamente, cavando así, todos unidos, la gente reunida cavando y plantando el terreno... (Ana, entrevista, 1 de mayo, 2009).

Ana acentuó que el trabajo en el rozado entrañaba una sociabilidad entre parientes y vecinos/as. Además, recordó que comenzó a trabajar allí con su padre.

$\mathrm{Al}$ igual que Ana, muchas de las mujeres que habitaron las tierras de Belém o que viven actualmente allí me hablaron de las diferentes labores que realizaron de forma permanente a lo largo del tiempo, entre las que se cuentan las tareas en la agricultura. La sociabilidad que esas tareas implicaban y el proceso de socialización por el que ellas atravesaban mientras las hacían son parte de sus relatos. Célia, una habitante del asentamiento que no llegaba todavía a los cincuenta años, describió los inicios de su trabajo en el rozado con la madre y el padre como un modo de comenzar a ver el mundo y a conocer las cosas del mundo, mientras que Teresinha, con el roçadinho [rozadito] que su padre le dio a los quince años, adquirió un "entendimiento" que le permitió conversar con los/as otros/as sobre temas de los que todos/as hablaban. ${ }^{7}$ Pero no únicamente en lo relativo a las actividades agrícolas se acentuaron sus diversas formas de sociabilidad.

\footnotetext{
7 El roçadinho es una plantación individual. En relación con pequeños productores de la Zona da Mata de Pernambuco, Brasil, Heredia (1979) y Garcia Jr. (1983) señalan que esa plantación individual puede pertenecer a cualquier miembro de la familia que no sea el padre, quien tiene el dominio del rozado.
} 
Diferentes tareas, como lavar la ropa, limpiar la casa y, sobre todo, aquellas ligadas a la cocina, asomaron ante mis preguntas. Teresinha me habló de una gran cantidad de tareas de las que tuvo que hacerse cargo con posterioridad a su casamiento. Además del rozado, tendría ahora que encargarse de la casa y de los animales que criaban. Teresinha limpiaba la casa, alimentaba a los cerdos y a las gallinas, cocinaba y lavaba la ropa para su familia, entre otras actividades que describió pacientemente. Cuando me dijo sobre la preparación de algunas comidas que en el pasado hacía de modo frecuente, no dejó de mencionar que las preparaba en gran cantidad y luego le daba a sus vecinas. Cuando me habló del lavado de ropas, también agregó sobre las relaciones implicadas en esa tarea que en una época se hacía en un lugar colectivo. ${ }^{8}$

Las vecinas acostumbraban a lavar ropa en un mismo embalse, contaba Teresinha, el cual pertenecía a la propiedad. Pero un día, aquello fue prohibido. Sólo ella pudo seguir usando el embalse, se lo permitió el capataz de un propietario, quien estaba de novio con una prima de Gregório. A pesar del pedido de Teresinha para que también se lo permitiera a sus vecinas, éstas ya no pudieron hacerlo. Así, por vergüenza de que las vecinas la vean usando el embalse, Teresinha iba a lavar escondida, cuando ya no había sol. Lavaba ropa en gran cantidad, todas las noches; no era para "ser bonita", no era "para mostrarse", no era para "exhibirse", lavaba -decía- porque le gusta la limpieza, porque le gusta tener su ropa limpia, y porque quería que sus hijos vayan limpios a la escuela. Todas las noches salía de su casa y partía hacia la oscuridad.

En Manaus, Jacinta fabrica instrumentos de barro en su casa. Tenía 64 años al momento de nuestro encuentro y ha vivido en esas tierras desde su nacimiento. Nuestra conversación se vio profundamente marcada por ese trabajo al que se dedicó desde pequeña.

Soplaba un viento agradable y nos sentamos en el frente de su casa, junto a Celine y la hija de Maria Clara. Las personas del lugar usaban utensilios de barro, mencionó Jacinta, y su madre, y después ella, los fabricaban. También primas y tías se abocaban a esa tarea. Antes lo hacía su abuela, que se lo enseñó a su mamá quien, a su vez, se lo enseñó a ella y así, ese saber fue atravesando las generaciones de mujeres de la familia. Jacinta cree que luego de su hija esa cadena será interrumpida, el trabajo es muy difícil y hoy las personas no le dan valor.

Jacinta trabaja por encomienda. Además, vende sus productos en la feria de la ciudad. Todos los domingos toma un automóvil que pasa por la ruta y va hacia allí: "hay días que se vende, días que no se vende, y es asî" (Jacinta, entrevista, 2 de mayo, 2009). Cuando era pequeña acompañaba a su madre a la feria, lo que era menos frecuente que la venta por encomiendas. A diferencia de hoy, en aquella época su madre vendía bastante. Entre los vecinos que le compraban se contaba el padre de Teresinha.

Sea en el rozado o en la casa, los relatos de las mujeres sobre sus trabajos no son independientes de los espacios de sociabilidad que éstos brindan. Como vimos con Teresinha, poder hablar sobre lo que sus vecinos hablaban gracias a su experiencia en el roçadinho, intercambiar comida con las vecinas (y recibir con comida a las visitas) por medio de su tarea en la cocina, reunirse con ellas en el lugar de lavar la ropa, cuidar del aspecto de su familia o poder presentar a sus hijos con el atuendo limpio en una institución pública como la escuela, son aspectos inseparables del trabajo. Por su parte, desde la olería que practica en su casa, Jacinta se relaciona con otras mujeres y va a la feria, como también lo hacía su madre, mientras que Ana y Célia (así como Teresinha) nos hablan del rozado como espacio de trabajo colectivo y de socialización en la vida del lugar.

\section{En la casa de harina}

La relevancia que en las narrativas de las mujeres toma la casa de farinha, donde se hacía harina de mandioca, es otro factor sugerente en ese sentido. Generalmente el tema se asocia a una época anterior, ya que en el presente aquella práctica no es tan extendida como lo era antes y habitualmente el proceso se hace en la propia casa y en poca cantidad. Si bien también algunos

\footnotetext{
8 Silva (2004) señala cómo el trabajo en la casa es percibido como individual aún en un asentamiento del Movimento dos Trabalhadores Rurais Sem Terra (MST), que en su proyecto promueve la construcción de relaciones igualitarias y la participación de las mujeres en organizaciones políticas (e.g. Schwade, 2014; Silva, 2004).
} 
hombres refirieron a ese asunto al hablarme de sus vivencias en el lugar, éste no formaba parte de la historia principal que me contaban. Entre las mujeres, en cambio, tuvo centralidad. Cuando me hablaron de la casa de farinha no dejaron de aludir al trabajo colectivo ni a las ocasiones de festejo que tenían lugar alli. ${ }^{9}$
"¿Y eran muchas personas las que hacían la harina?". Le pregunté a Antônio de Serras, un antiguo habitante del lugar.
"Era demasiada gente, eran más de treinta mujeres, solo para pelar la mandioca...", me respondió.
"¿Y eran hombres y mujeres?".
"Eran más mujeres. Había hombres también, solo molían los hombres...". ${ }^{10}$ (Antônio, entrevista, 20 de mayo, 2009).

"Tava na peneira / Eu tava peneirando / Eu tava no namoro / Eu tava namorando": como en la canción de Luiz Gonzaga, la farinhada abría espacio a los noviazgos. Teresinha "solo tenía trabajo en la vida" y trabajando en la casa de farinha conoció al joven que vivía del otro lado del río y era cinco años mayor que ella. Era Gregório, con quien luego se casó. Tenía doce años cuando lo conoció.

Ya desde los diez que Teresinha pelaba mandioca para su padre cuando era la farinhada, la cual podía llegar a durar un mes. Siempre trabajó en la casa de farinha, hasta que tuvo alrededor de cincuenta años: "yo ayudaba a la gente, a los vecinos, y ahí los vecinos venían a ayudarme" (Teresinha, entrevista, 3 de junio, 2009). Además de las mujeres que pelaban, también había hombres -entre los que se encontraba su padre- que molían la mandioca con la rueda y la revolvían durante su cocción. Algunas mujeres mencionaron a los trabajadores que sus padres pagaban para aquel trabajo, pero en general se refirieron a la familia, a los parientes y a los vecinos que estaban presentes y "ayudaban" en ese proceso. Entre mímicas y detalles, Teresinha y otras mujeres me describieron aquella tarea, y hablaron en seguida del beiju que preparaban (y preparan) con esa harina, comida que tuve el gusto de probar en el asentamiento y de recibirlo como un regalo que más de una mujer me hizo.

Cuando era el momento de hacer harina con su mandioca, el padre de Teresinha llamaba a otras personas para participar de aquello. Antes era necesario pedir la casa de farinha al dueño, ya que solían ser muy requeridas. Una vez que ésta estaba disponible comenzaba la farinhada. Se iniciaba los lunes. Teresinha se dirigía de la casa de su padre a la de su abuela, que se encontraba próxima a la casa de farinha, y de lunes a domingo pelaba, rallaba y cernía. El lunes siguiente empezaba de nuevo, y así hasta que se acababa la mandioca.

El dueño de la casa podía ser el dueño de las tierras o también un morador de mayores recursos que los demás.

Además de implicar un trabajo colectivo, en el "tiempo de la farinhada", como algunos/as habitantes del lugar lo llamaron, también había festejos. "Uno mataba un chancho para hacer, para comer en la casa de farinha, era una buena época. La gente se ajuntava, a veces pagaba también ¿sabes? Si la familia quisiese iba a ayudar" (Jacinta, entrevista, 2 de mayo, 2009). ${ }^{11}$

\section{En la galería}

El lugar de sociabilidad que el trabajo toma en los relatos de las mujeres no se hizo visible únicamente cuando me contaron de su pasado. Durante el trabajo de campo, hubo días en los cuales me preocupaba ver como las horas transcurrían y yo continuaba en la casa de Teresinha. Ahí

\footnotetext{
${ }^{9}$ Las casas de farinha como espacios de sociabilidad y festejo entre vecinos es un aspecto enfatizado en la bibliografía (e.g. Caldeira, 1956).

${ }^{10}$ Para una descripción detallada del proceso en la casa de farinha ver Heredia (1979) y Garcia Jr. (1983). Esos trabajos también llaman la atención sobre las casas de farinha como puntos de encuentro donde se refuerzan las relaciones sociales.

${ }^{11}$ Galvão (1954) -citado en Caldeira (1956)- llama la atención sobre las categorías adjunto y ajuda para denominar al auxilio mutuo en el sertão de Rio Grande do Norte.
} 
me quedaba, nadie podía ir conmigo en mi recorrido de conversaciones sobre Belém o la persona recomendada para hablar no estaba. Permanecía en la galería de la casa, acompañando a Teresinha en su trabajo, o conversando con las mujeres que se reunían de forma frecuente en ese lugar. Y ahí me quedaba, sin poder hablar de Belém. A pesar de la preocupación y ansiedad que aquello me generaba fue esa insistente frustración la que me ayudó a advertir que "Belém" era mucho más de lo que pensaba y que ella también encerraba un mundo público vivido por mujeres del que no me pude percatar a primera vista.

La porción de la galería entre la cocina y el patio, y también la cocina, fueron espacios que me mostraron una dinámica de encuentros femeninos y me permitieron percibir la sociabilidad que el trabajo implica (e implicó) para las mujeres. No sólo "visitarse", sino también "ayudarse" en el trabajo transformaba esos lugares en zonas donde ellas se reunían. Teresinha solía recibir frecuentemente a sus vecinas del asentamiento que "pasaban" por allí y eran atendidas en la galería, que a diferencia de la sala, era habitada cotidianamente con actividades laborales. También ahí recibía "visitas", las cuales venían de más lejos y podían ser familiares o vecinas antiguas que vivían en otra comunidad. Si las personas llegaban después del almuerzo o de la cena encontraban a Teresinha en su descanso. En esos momentos ella se sentaba en una silla y conversaba o, cuando era la siesta, dormitaba con las conversaciones. En otros momentos, se ocupaba en diversas tareas que muchas veces la hacían desplazarse desde la cocina al patio, de manera que, desde la galería, las vecinas podían acompañar sus movimientos mientras hablaban.

Las vecinas generalmente estaban "de pasada" y aquello servía de excusa para detenerse en la casa de Teresinha. Algunas hacían pasajes más sistemáticos. Daniela, por ejemplo, quien vivía enfrente, se dirigía allí todas las siestas y permanecía un tiempo sentada en la galería, mientras le daba un descanso a su cuerpo que se transformaba día a día para albergar a otro cuerpo en gestación. En la galería, las mujeres también se reunían para pintarse las uñas, y con eso creaban tardes de brillos y colores que brindaban la posibilidad de encuentros sistemáticos.

Si Teresinha estaba trabajando, las vecinas la "ayudaban" a realizar su tarea cuando eso era posible. Por otra parte, el trabajo de todos los días no era hecho únicamente por Teresinha. Las actividades requerían que su hija Consolação, su nieta Marcela y a veces su nuera Mariana y la joven esposa de su nieto, Alice, también las ejecuten. De este modo, a lo largo de la jornada, a excepción de la siesta y del momento posterior a la cena, el patio, la galería, la cocina y el corral donde se guardaban los chivos y las cabras, se volvían espacios de intensa circulación femenina. Lavar los platos, desvainar porotos y separar los porotos en buen estado eran las tareas donde Teresinha recibía casi toda la ayuda de estas mujeres (como también de sus vecinas), que algunas veces, después de preparar el almuerzo en sus respectivas casas, iban a almorzar a lo de Teresinha. Con Marcela era diferente, ya que ella vivía allí y su responsabilidad era mayor. Generalmente, Marcela cocinaba el almuerzo y limpiaba la casa. Las tareas del patio quedaban a cuenta de Teresinha, como también el lavado de ropas, la preparación del desayuno para Gregório, para los trabajadores y para el resto de los miembros de la casa y la cena (Marcela iba a la escuela de noche y no podía prepararla). ${ }^{12}$

Al "ayudarse", las mujeres hacían del trabajo un espacio de sociabilidad; cooperar en las tareas les permitía reunirse. Más allá de las ayudas que la hija, las nueras y la nieta (y también los nietos) le ofrecían a Teresinha, ellas iban frecuentemente a la galería a realizar sus propias tareas. Consolação y Alice iban a tejer croché, un tejido que se transformaba luego en el vestido de una muñeca de botella de gaseosa que, no mucho tiempo atrás, habían aprendido a hacer para vender. Además, Consolação, que vivía en una casa contigua a la de Teresinha, acostumbraba a separar allí los porotos, pelar la mandioca y tamizarla, mientras que Mariana (que también vivía en una casa contigua) se presentaba de modo frecuente con su revista de ventas de productos de perfumería, bijouterie y ropa. Cuando podían, el trabajo era realizado en compañía, o más exactamente, el trabajo les permitía la compañía. La sociabilidad femenina se forjaba en gran medida en torno a una circulación laboralmente regida. Todo esto hacía de la casa, específicamente, de la galería, de la cocina y del patio, lugares públicos controlados por mujeres.

\footnotetext{
${ }^{12}$ En la casa vivían Marcela, Teresinha y Gregório. Zé Paulo -el hijo menor de ambos- y Zeferino -pariente de una ex esposa de Gregório- también vivían allí, aunque dormían en un cuarto con entrada independiente.
} 


\section{En la capilla}

Era primero de mayo y yo estaba en Manaus. Mientras "paseaba" por allí con Celine, Maria Clara y su madre Adelina veía en cada casa un intenso movimiento de cocina, una organización de mujeres con el objetivo de preparar pamonha y canjica. ${ }^{13}$ En el asentamiento, antes de partir a Manaus, fue posible apreciar el mismo movimiento. Teresinha se alistaba para la cocina y reunía a sus ayudantes. Como Marcela iría conmigo a Manaus, Mariana la reemplazaría. En ambos lugares, se haría a la noche el rezo del primero de mayo, el primer terço del mes. En Manaus, Celine pasó la tarde conversando con sus parientes mujeres para organizar la salida a la capilla de Boa Fé, una comunidad próxima de allí, donde esa misma noche tendría lugar el terço. El evento motivó además la visita de su sobrina, que fue a su casa para ayudarla a estilizar su cabello y adornar sus manos.

Cuando llegamos con Marcela al asentamiento ya era de noche, Teresinha estaba en su casa con Consolação y algunas vecinas, todas arregladas y listas para ir al terço que se realizaría en la capilla católica del lugar, la cual fue construida en el centro del asentamiento. Su llave queda a cargo de tres mujeres que viven allí. ${ }^{14}$

La próxima noche de terço que estuve en el asentamiento, Teresinha, más allá de mis creencias, me invitó, y a partir de entonces comencé a frecuentarlos. Los rezos de mayo y las narrativas de las mujeres sobre un pasado de fiestas religiosas me volvieron a mostrar lugares de intensa sociabilidad femenina. Más aún, la dinámica religiosa recreada en el lugar se reveló como un espacio de dominio de las mujeres.

El terço tenía lugar todas las noches de mayo, a excepción de los fines de semana. En la capilla del asentamiento se reunían varias mujeres ya casadas, niños/as y algunas jóvenes solteras que vivían allí, como también unos pocos hombres que generalmente acompañaban a sus esposas. Se realizaba en el horario de la escuela secundaria, de modo que había una escasa presencia de jóvenes comprendidos/as en esa edad escolar.

Luego de las siete de la tarde comienzan a sonar las campanas de la pequeña capilla. Eso significa que el terço está por comenzar. Las luces se encienden y la música empieza a sonar. Algunas mujeres ya están reunidas en lo de Teresinha, cuya casa se ubica enfrente a la capilla. Termino pronto de tomar el té con hojas de laurel, capim santo y naranja. Es el té posterior a la cena. Doralice -una vecina de Teresinha que la visitaba habitualmente-, Consolação y su hijo más pequeño, Edmundo, Teresinha y yo partimos al rezo. Débora, otra vecina, vuelve a su casa, a pesar de la insistencia de las mujeres para que vaya con ellas. En general, esa era la dinámica. Íbamos en grupo y volvíamos también así. A veces junto a Dona Lurdes, a Zefinha -ambas antiguas habitantes del lugar, que viven próximas a la casa de Teresinha- $\mathrm{u}$ otras vecinas.

Zefinha se encarga de dirigir el evento y con ella colabora siempre el mismo grupo de jóvenes. No hay allí sacerdotes. La presencia de mujeres casadas es sobresaliente entre quienes concurren. También hay varios niños y varias niñas que se sientan en las sillas de adelante o en las gradas del altar. Un pasillo divide los asientos de los/as asistentes en dos conjuntos. Además, se hallan algunos íconos de santos y santas colgados en las paredes. Entre ellos destaca Nossa Senhora de Aparecida que se encuentra en el centro del altar, debajo de la imagen de Jesús.

El terço suele durar poco más de media hora. Allí se reza parte del rosario (un tercio), se canta y se leen versículos de la biblia. Luego, Zefinha o alguna de sus ayudantes realizan una breve reflexión sobre la lectura o las canciones entonadas.

Como último paso las personas se dan la paz, lo que genera un movimiento que suele ir de las primeras a las últimas filas. Antes ocurre un momento central del terço en el cual se besa a la santa, Nossa Senhora da Conceição, y se le entrega flores. La estatuilla de la santa se encuentra colocada sobre una mesa adornada con flores que luego las personas toman para hacer su entrega. Cada mujer casada tiene su noche de rezo. Ella será la encargada de recoger las flores para esa noche y para aquello puede recibir la ayuda de sus familiares y/o vecinas. Es preciso que en las

\footnotetext{
${ }^{13}$ Se trata de comidas típicas que se preparan con maíz.

${ }^{14}$ Algunas mujeres también frecuentan otras instituciones religiosas, entre ellas las iglesias evangélicas. Las mismas no poseen templo en el asentamiento y sus misas se celebran en las casas de los/as participantes.
} 
flores estén contemplados tres colores: el blanco, el amarillo y el rojo. El blanco se asocia con los/as más pequeños/as, el amarillo con las "doncellas", es decir, las mujeres jóvenes y solteras, y el rojo con las mujeres casadas.

El canto comienza a sonar y la quietud de la sala se altera. Se levantan los/as niños/as y forman una fila a lo largo del pasillo frente a la mesa de flores que se encuentra debajo del altar. Uno/a por uno/a besa su flor y la entrega, algunos/as también besan a la santa, y luego se persignan doblando las piernas hasta quedar casi arrodillados/as. Cuando los/as niños/as se sientan, se levantan las pocas "doncellas" que hay en la sala con sus flores amarillas. Finalmente, llega el gran movimiento y las flores rojas comienzan a circular.

Entre las canciones que eran entonadas en el evento una de ellas llamó especialmente mi atención: "Ave llena de gracia/ Ave llena de amor/Salve la madre de Jesús aquí nuestro canto y nuestro loor". Ese era el estribillo de un canto que, dijo un día Zefinha, "habla de nuestra realidad":

\section{Madre del creador, rogad \\ Madre del salvador, rogad \\ Del libertador, rogad por nosotros. \\ Madre de los oprimidos, rogad \\ Madre de los perseguidos, rogad \\ De los desvalidos, rogad por nosotros.}

En los terços la santa toma un lugar de relieve y quienes se comunican con ella son las mujeres. Para esta comunicación los cantos y los ruegos se vuelven la forma privilegiada de enunciación. El canto es la expresión por excelencia de un mundo público de mujeres que la sola narración en prosa no es capaz de dar cuenta en su totalidad. Si la canción de la cual cité una estrofa "habla de su realidad", esa "realidad" queda también contenida en la santa. La santa es la gran Madre, la Madre de todos y de toda esa "realidad" que describe la canción. Si ellos pueden ser entrevistados y pueden contar a los otros sobre los "esclavos", los "perseguidos" y los "oprimidos" temas que se destacaban cuando me contaban sobre Belém-, son ellas las que cantan sobre aquello a la "Madre" y le piden su ruego. Son las mujeres del asentamiento quienes piden por ese acto, y se reúnen en el lugar de su "Madre", y la homenajean, y cantan, y ruegan también ellas, le ruegan por esa "realidad".

Como me referí en la introducción, las diversidades culturales en relación con las nociones de madre y maternidad han sido ampliamente analizadas desde la antropología. En este sentido, me parece interesante destacar también las diferentes situaciones en que dicha noción se activa y remarca distintos significados, como en este caso es la comprensión de la "madre" como una figura venerable, al asociarse con la madre de Jesús. Trabajos contemporáneos en torno a movilizaciones de madres cuyos hijxs han sido víctimas de violencia evidencian un aspecto semejante de la noción. En tal sentido, más que para señalar el confinamiento de las mujeres, la idea de "madre" actúa como "elemento de autoridad moral en actos políticos" (Vianna; Farias, 2011:83) que permite legitimar el luto y las relaciones domésticas que han sido rotas como un asunto público. En lugar de reafirmar la separación entre una pérdida personal y un problema social, la "madre" transita en tales casos borrando los límites de aquello que se clasifica como público o privado (Vianna; Farias, 2011; Efrem Filho, 2017).

La santa es homenajeada, en su mayoría, por mujeres y niños que se juntan en la capilla. Son esas mismas mujeres las que tienen la llave del lugar de la santa y quienes organizan, realizan y coordinan ese evento público. El terço nos muestra que con la religión las mujeres establecen circuitos de desplazamiento que no se rigen únicamente por el trabajo, también con la religión ellas recrean espacios de sociabilidad que se vuelven predominantemente femeninos.

Los espacios públicos que las mujeres construyen con su vivencia religiosa no se restringen al presente. En sus relatos ellas los presentan en continuidad con el pasado. Como ocurre con el trabajo, la religión significa para las mujeres un ámbito público y, por eso, es un asunto digno de ser narrado para mí cuando se refieren a su vivencia en el lugar. Si, como señala Grima (1991), entre las mujeres pastunes el "sufrimiento" es algo con valor para ser contado, entre las mujeres de Belém 
despunta el relato de una cotidianeidad que perdura y que nos habla de sus ámbitos de relación con la comunidad.

\section{Consideraciones finales}

El trabajo de las mujeres y sus vivencias religiosas, del pasado y del presente, oídos en sus narrativas y apreciados día a día durante el campo, traen aspectos que ellas consideran dignos de ser contados, de ser pasados a alguien de afuera del lugar que se interesa por sus historias. Sin embargo, éstos no podrían haber sido contados si mi presencia allí se hubiese limitado a seguir el circuito recomendado de "entrevistas" sobre Belém, compuesto por habitantes antiguos y, sobre todo, por varones.

En efecto, correspondía a los hombres contar a una persona que no era de allí, así como contar sobre Belém y su "historia". Su poder de acceso a la palabra pública le daba a sus narrativas un carácter de mayor publicidad, ampliaba su margen de oyentes a quienes no eran estrictamente de su universo cotidiano.

A las vivencias de las mujeres accedí, en cambio, a partir de un vínculo que sí se enmarcaba en su universo cotidiano. Más que como universitaria y extranjera, entré como una visita, quien mientras hacía su trabajo se alojaba en la casa de Teresinha y acompañaba diariamente las tareas que ella realizaba. Pasé a ser identificada como alguien perteneciente a su mapa de relaciones y, desde esa red más íntima, las mujeres se relacionaron conmigo. Para poder conversar tranquilamente con ellas fue necesario que ingresase a sus modos cotidianos de sociabilidad, que ocupase allí una posición. No podría haberme vinculado desde mi lugar de universitaria. Éste implicaba la apertura a un círculo de relaciones que no era apropiado para ellas. Sería más adecuado que de ese contacto se ocupasen sus maridos.

A pesar de requerir mayor intimidad y personalización, esas relaciones que establecí con las mujeres me permitieron ver una parte de aquello que había para contar y que no era la historia. De aquello que era público, en el sentido que remitía a experiencias de participación en la vida social, pasibles de ser transmitidas a una audiencia mayor, pero que se contaba de forma silenciosa.

Los relatos de las mujeres sobre sus actividades van acoplados a los vínculos que allí se despliegan. El trabajo en el rozado, en la cocina o con el barro, las vivencias religiosas, entre otras, constituyen para las mujeres sus ámbitos de sociabilidad $\mathrm{y}$, como tales, se vuelven meritorios de serme contados, de ser contados a una investigadora que se relaciona con ellas como una visita. Desde aquí las mujeres instalan otras narrativas sobre el pasado en el lugar, diferentes de la historia de Belém que los varones cuentan.

Así, si sólo desde un circuito de relaciones personales pude acceder a la palabra de las mujeres, ese circuito no me abrió únicamente un mundo íntimo o privado, sino un mundo público. Si por normas sociales no eran las mujeres quienes en una primera instancia contaban lo público, sí lo hacían de una forma menos explícita, cuando mi relación con ellas no era la de la investigadora que iba a entrevistar, sino la de "Fernanda", quien "visitaba" a Teresinha y también a otras personas.

Abu-Lughod (1999) muestra que hombres y mujeres beduinos/as del árido Egipto adhieren, en su discurso ordinario, a los ideales morales del honor y la modestia. Sin embargo, en el discurso de la poesía, de los ghinn\was, las mujeres y hombres jóvenes expresan los sentimientos de la intimidad que desafían los ideales morales a los que adhieren en otro plano. Ese análisis brinda herramientas para pensar el hecho de que las mujeres de Belém no asumen voluntariamente la palabra Pública pero sí lo hacen de modo no explícito, la asumen en un ámbito velado. Si en una determinada esfera ellas adhieren al ideal moral de no ser quienes hablan del mundo Público, en otra, en una esfera de menor exposición, ellas sí hablan del mundo público, pero de uno que se revela diferente del primero. Las mujeres narraban para mí en el ámbito de las relaciones personales, donde yo ya no era alguien que se interesaba por temas de interés general del cual los hombres me tenían que informar, sino que era otra mujer que estaba de visita en la casa y conversaba con otras mujeres sobre temas que principalmente les competía a ellas. Eran temas no hegemónicos. En esas conversaciones invisibles ellas me hablaban de sus espacios de relación con la comunidad y disputaban así un mundo público y la posibilidad de contarlo. En lo invisible, en un 
ámbito que los varones y los menos allegados no registran, las mujeres de Belém instalan, de un modo paradójico, sus espacios públicos.

Cantar, ir a la capilla, trabajar en el rozado, pintarse las uñas, cocinar, modelar el barro, tejer croché, rezar, conversar en la galería de la casa, desvainar porotos, pelar la mandioca eran actividades que me mostraron modos de expresión públicos, modos alternativos de contarme sobre "Belém" y la vida del lugar, que difícilmente se abrían con las preguntas acerca de la historia, el conflicto sindical o el trabajo obligado de los moradores. Lo personal abría también lo público y esa constatación me recordó el llamado de Fraser (1997) a atender las formas diversas en que las personas acceden a la vida pública y a considerar los "contra-públicos" que disputan por esas formas alternativas. Y, sobre todo, me recordó su convocatoria a tener en cuenta el significado político de una separación conceptual que, al relegar determinados asuntos al ámbito de lo privado, permite deslegitimarlos como parte del interés público.

Las mujeres que permanecen en sus casas, las mujeres que me cuentan en esferas más íntimas y personalizadas, las mujeres que no desean ser entrevistadas sobre la organización sindical, no por eso están en un ámbito "privado". Desde sus casas, las cocinas o sus círculos de sociabilidad, recrean otros espacios públicos y otras maneras de contar el pasado. Lo que quisiera destacar en este artículo es la importancia de esos otros espacios y modos de contar, la necesidad de encarar los ámbitos domésticos, la casa, o las esferas donde predomina una circulación femenina como otro universo público. De evitar su marginalización del interés científico al aducir un supuesto carácter privado que los relega a la oscuridad académica. De resaltar las relaciones de poder que también operan por detrás de nuestras clasificaciones. Como podemos observar en los trabajos de Abu-Lughod (1999), Grima (1991), Mills (1991), Ramanujan (1991), Rosaldo (1974) y Woortmann (1992), entre otros, gran número de estudios, hechos históricamente por científicos en su predominio varones, se han abocado a universos masculinos y han forjado un sentido común académico en torno a aquello digno de ser observado. Con este trabajo, no pretendo mostrar, como suele hacerse y como efectivamente ocurre en las tierras de Belém, cómo las mujeres también participan de actividades controladas y ejercidas mayormente por varones. A diferencia de eso, me interesa dejar en evidencia la necesidad de rescatar aquellas otras actividades en las que los varones no son protagonistas y que, desde nuestras preconceptos sobre lo relevante de atender en los análisis socioculturales, parecen no importarnos, como en este agreste nordestino lo son, por ejemplo, la casa, la cocina, la maternidad, o el día a día de las relaciones entre mujeres.

\section{Referencias bibliográficas}

ABU-LUGHOD, Lila. Veiled Sentiments. Honor and Poetry in a Bedouin Society. Berkeley, University of California Press, 1999.

ALMEIDA, Alfredo Wagner de; ESTERCI, Neide. Quixadá: A formação do povoado e o aceso à terra pelos pequenos produtores. In: Projeto Emprego e Mudança Sócio Econômica no Nordeste. Rio de Janeiro, Museu Nacional/UFRJ, 1977a. Mimeo.

ALMEIDA, Alfredo Wagner de; ESTERCI, Neide. Terras soltas e o avanço das cercas. In: Projeto Emprego e Mudança Sócio Econômica no Nordeste. Rio de Janeiro, Museu Nacional/UFRJ, 1977b. Mimeo.

BASTOS, Eliane Cantarino O'Dwyer. A cultura de algodão no sertão paraibano. Rio de Janeiro, Museu Nacional/UFRJ, n.d. Mimeo.

CALDEIRA, Clovis. Mutirão. Formas de Ajuda Mútua no Meio Rural. São Paulo, Companhia Editora Nacional, 1956.

CARSTEN, Janet. Introduction: Cultures of Relatedness. In: CARSTEN, Janet (ed.). Cultures of Relatedness: New Approaches to the Study of Kinship. United Kingdom, Cambridge University Press, 2000, pp.1-36.

CASCUDO, Luís da Câmara. Tradiçóes populares da pecuária nordestina. Rio de Janeiro, Ministério da Agricultura, Serviço de Informação Agrícola, 1956.

DAVIS, Angela. O legado da escravidão: parâmetros para uma nova condição da mulher. In: DAVIS, Angela, Mulheres, raça e classe. São Paulo, Boitempo, 2016, pp. 23-48. Traducción: Heci Regina Candiani. 
EFREM FILHO, Roberto. A reivindicação da violência: gênero, sexualidade e a constituição da vítima. cadernos pagu (50), Campinas, SP, Núcleo de Estudos de Gênero-Pagu/Unicamp, 2017 [https://doi.org/10.1590/18094449201700500007 - acceso el 5 de junio de 2021].

ELIAS, Norbert. La Sociedad Cortesana. México, Fondo de Cultura Económica, 1996.

FIGURELLI, M. Fernanda. Cuando ellas cuentan: Relaciones de género y narrativas históricas sobre una antigua propiedad rural. Etnográfica 25(2), pp.315-334 [https://doi.org/10.4000/etnografica.9648 - acceso el 19 de octubre de 2021].

. Historias de familia, historias de propiedad: Dinámicas de parentesco en torno a un antiguo latifundio del Nordeste de Brasil. Revista de Antropologia 60(1), 2017, pp.242-262 [doi: http://dx.doi.org/10.11606/2179-0892.ra.2017.132075 -acceso el 5 de junio de 2021].

Família, Escravidão, Luta: Histórias Contadas de Uma Antiga Fazenda. Tese (Doutorado em Antropologia), Museu Nacional, UFRJ, Rio de Janeiro, 2011.

FRASER, Nancy. Pensando de nuevo la esfera pública. Una contribución a la crítica de las democracias existentes. In: FRASER, Nancy (ed.). Iustitia Interrupta. Reflexiones críticas desde la posición "postsocialista". Bogotá, Siglo del Hombre Editores, 1997, pp. 95-133.

GARCIA JR., Afrânio Raul. Terra de Trabalho. Rio de Janeiro, Paz e Terra, 1983.

GONZALEZ, Lélia. Racismo y sexismo en la cultura brasileña. In: BRINGEL, Breno y BRASIL, António (ed.). Antología del pensamiento crítico brasileño contemporáneo. Ciudad Autónoma de Buenos Aires, CLACSO, 2018, pp.565-584.

GRIMA, Benedicte. The Role of Suffering in Women's Performance of Paxto. In: APPADURAI, Arjun; KOROM, Frank J.; MILLS, Margaret (ed.). Gender, Genre, and Power in South Asian Expressive Traditions. Philadelphia, University of Pennsylvania Press, 1991, pp.78-101.

HEREDIA, Beatriz María Alasia de. A morada da vida: trabalho familiar de pequenos produtores do nordeste do Brasil. Rio de Janeiro, Paz e Terra, 1979.

JELIN, Elizabeth. Subjetividad y esfera pública: El género y los sentidos de familia en las memorias de la represión. Política y sociedad 48(3), 2011, pp.555-569 [doi:10.5209/rev_POSO.2011.v48.n3.36420 acceso el 10 de diciembre de 2018]

JOHNSON, Allen W. Sharecroppers of the Sertão. Economics and Dependence on a Brazilian Plantation. Stanford, Stanford University Press, 1971.

LEYDESDORFF, Selma; PASSERINI, Luisa; THOMPSON, Paul (ed.). Gender and Memory. New York, Routledge, 2017 [1996].

MARCELIN, Louis Herns. A linguagem da casa entre os negros no recôncavo baiano. Mana 5(2), 1999, pp.31-60 [https://dx.doi.org/10.1590/S0104-93131999000200002 - acceso el 20 de septiembre de 2017].

MARQUES, Ana Claudia (ed.). Conflitos, politica e relaçôes pessoais. Campinas, Pontes, 2007.

MOORE, Henrietta. Antropología y feminismo, 5ta Ed. Madrid, Cátedra, 2009 [1991].

OKIN, Susan Moller. Gênero, o público e o privado. Revista Estudos Feministas 16(2), 2008 (1991), pp.305332 [http://dx.doi.org/10.1590/S0104-026X2008000200002 acceso el 30 de junio de 2018]

ORTNER, Sherry. ¿Es la mujer con respecto al hombre lo que la naturaleza con respecto a la cultura? In: HARRIS, Olivia; YOUNG, Kate (ed.). Antropología y feminismo, Barcelona, Anagrama, 1979, pp.109-131 [1974].

PALMEIRA, Moacir; BARREIRA, Cesar (ed.). Politica no Brasil: visóes de antropólogos. Rio de Janeiro, Relume Dumará, Núcleo de Antropologia da Política/UFRJ, 2006.

PERROT, Michelle. Mi historia de las mujeres. Buenos Aires, Fondo de Cultura Económica, 2008. Traducción: Mariana Saúl.

RAMANUJAN, A. K. Toward a Counter-System: Women's Tales. In: APPADURAI, Arjun; KOROM, Frank J.; MILLS, Margaret (ed.). Gender, Genre, and Power in South Asian Expressive Traditions. Philadelphia, University of Pennsylvania Press, 1991, pp.33-55. 
ROSALDO, Michelle Zimbalist. The Use and Abuse of Anthropology: Reflections on Feminism and CrossCultural Understanding. Signs 5(3), 1980, pp.389-417.

Woman, Culture, and Society: A Theoretical Overview. In: ROSALDO, Michelle; LAMPHERE, Louise (ed.). Woman, Culture, and Society. Stanford, Stanford University Press, 1974, pp.17-42.

SCHWADE, Elisete. Gênero e ativismo político: mulheres no MST e em assentamentos rurais. In: ASSIS, Gláucia; MINELLA, Luzinete; FUNCK, Susana (ed.). Entrelugares e mobilidades, Tubarão, Copiart, 2014, pp.229-248.

SILVA, Cristiani Bereta. Relações de gênero e subjetividades no devir MST. Revista Estudos Feministas 12(1), 2004, pp.269-287.

STRATHERN, Marilyn. Domesticity and the Denigration of Women. In: O'BRIEN, Denise; TIFFANY, Sharon (ed.). Rethinking Women's Roles: Perspectives from the Pacific. Berkeley, University of California Press, 1984, pp.13-31.

VIANNA, Adriana; FARIAS, Juliana. A guerra das mães: dor e política em situações de violência institucional. cadernos pagu (37), Campinas, SP, Núcleo de Estudos de Gênero-Pagu/Unicamp, 2011, pp.79-116 [https://doi.org/10.1590/S0104-83332011000200004 - acceso el 5 de junio de 2021].

WEBER, Florence. Lares de cuidado e linhas de sucessão: algumas indicações etnográficas na França, hoje. Mana 12(2), 2006, pp.479-502 [https://dx.doi.org/10.1590/S0104-93132006000200009 - acceso el 26 de mayo de 2014].

WOORTMANN, Ellen. O ambiente e a mulher: O caso do litoral do Rio Grande do Norte, Brasil. Latin American Studies 12, 1992, pp.30-53.

YANAGISAKO, Sylvia Junko. Family and Household: The Analysis of Domestic Groups. Annual Review of Anthropology 8, 1979, pp.161-205 [https://doi.org/10.1146/annurev.an.08.100179.001113 - acceso el 15 de mayo de 2014]. 